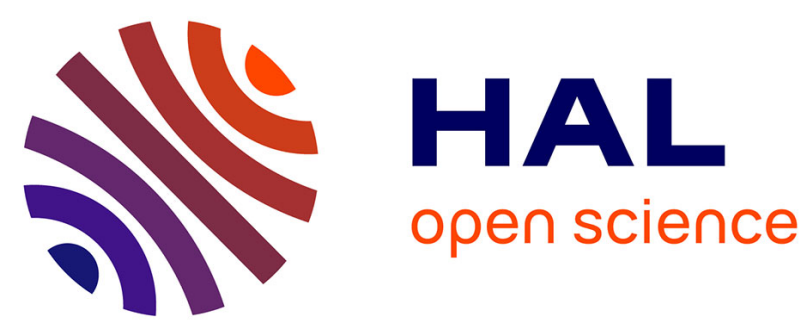

\title{
Self-administered questionnaire and direct observation by checklist: comparing two methods for physical exposure surveillance in a highly repetitive tasks plant.
} Alexis Descatha, Yves Roquelaure, Sandrine Caroly, Bradley Evanoff, Diane Cyr, Jean Mariel, Annette Leclerc

\section{To cite this version:}

Alexis Descatha, Yves Roquelaure, Sandrine Caroly, Bradley Evanoff, Diane Cyr, et al.. Selfadministered questionnaire and direct observation by checklist: comparing two methods for physical exposure surveillance in a highly repetitive tasks plant.. Applied Ergonomics, 2009, 40 (2), pp.194-8. 10.1016/j.apergo.2008.04.001 . inserm-00282977

\section{HAL Id: inserm-00282977 https://www.hal.inserm.fr/inserm-00282977}

Submitted on 28 May 2008

HAL is a multi-disciplinary open access archive for the deposit and dissemination of scientific research documents, whether they are published or not. The documents may come from teaching and research institutions in France or abroad, or from public or private research centers.
L'archive ouverte pluridisciplinaire HAL, est destinée au dépôt et à la diffusion de documents scientifiques de niveau recherche, publiés ou non, émanant des établissements d'enseignement et de recherche français ou étrangers, des laboratoires publics ou privés. 
Self-administered questionnaire and direct observation by checklist: comparing two methods for physical exposure surveillance in a highly repetitive tasks plant.

Alexis Descatha ${ }^{1,2}$, Yves Roquelaure $^{3}$, Sandrine Caroly $^{4}$, Bradley Evanoff ${ }^{5}$, Diane Cyr ${ }^{1}$, Jean Mariel $^{6}$, Annette Leclerc ${ }^{1}$

${ }^{1}$ INSERM, U687, Saint-Maurice, F-94410, France ; Université Paris XI, IFR69, Villejuif, F94807, France ; Université Versailles-Saint Quentin, Faculté de Médecine Paris-Ile-de-

France-Ouest, France

${ }^{2}$ Occupational health department, Poincaré teaching hospital AP-HP, Garches, France

${ }^{3}$ Laboratory of Ergonomics and Occupational Health, Angers, France

${ }^{3}$ Laboratory of Ergonomics "CRISTO", Grenoble, France

${ }^{5}$ Division of General Medical Sciences, Washington University School of Medicine, St.

Louis, United States

${ }^{6}$ Occupational Health Service of Anjou, Angers, France

Correspondence and reprints: Alexis Descatha, Unité de pathologie professionnelle, Hopital Poincaré, 104 bd Poincaré, 92380 Garches, France Tel: +33 (1) 471077 54; Fax: +33 (1) 471077 68; email: alexis.descatha@ rpc.aphp.fr Running title: Comparison of two methods for physical exposure surveillance 


\begin{abstract}
Background. We evaluated the agreement between a questionnaire and an observational checklist for exposure assessment in the setting of an upper-limb work-related musculoskeletal disorders (UWMSD) surveillance program in a population with a high level of physical exposures.
\end{abstract}

Methods. A surveillance program was implemented in a large shoe factory. Physical exposures were assessed in 1996 by a self-administered questionnaire and by the direct observation of work tasks assessed using a checklist filled out by trained assessors. Items were summed into a "questionnaire" score and an "observational" score. These scores were compared by Pearson's correlation. The association between exposure assessment by each method and UWMSD incidence between 1996 and 1997, defined by a standardized examination, was also studied.

Results. Correlation between the "questionnaire" score and the "observational" score was low among the 196 workers (77\%) who received both evaluations (rho=0.06 p>0.05). Only exposure assessed by the questionnaire method was significantly associated with high incidence of UWMSD between 1996 and 1997, with good sensitivity (97\%) and poor specificity $(27 \%)$.

Conclusion. In this surveillance program, self-reported physical exposures assessed by questionnaire and by direct observation did not evaluate same dimensions of high physical exposures. In this sample, exposures assessed by questionnaire identified workers at high risk of incident UWMSD more precisely than exposures identified by direct observation.

Key words $=$ musculoskeletal disorders, questionnaire, physical exposure surveillance. 


\section{INTRODUCTION}

Upper-limb work-related musculoskeletal disorders (UWMSD) are an important problem in industrial countries. There is strong evidence for an association between biomechanical exposures and these disorders (Hagberg et al. 1995; Roquelaure et al. 2002;Bernard BP 1997). Various assessment methods of biomechanical exposures are available, including selfreported methods using questionnaires, observational methods using checklists, video or computer analyses, and direct measurements of posture and local muscle fatigue (Li and Buckle 1999). In the context of surveillance, observational methods and direct measurements are often too expensive to apply to a large number of persons and exposures variables, while questionnaires are less expensive. Some authors have proposed a two-stage surveillance method for work exposure, with the first stage based on questionnaire (Scientific committee for musculoskeletal disorders of the ICOH 1996;Hagberg et al. 1995;Ricci et al. 1998).

Although some studies have evaluated the reproducibility and the validity of self-reported physical exposure by comparing them to observational methods and direct measurement (Stock et al. 2005), very few of them have focused on the validity of the self-reported biomechanical exposures in a surveillance setting, especially in populations with high level of physical exposure.

The purpose of this study was to compare self-reported exposures with those derived from direct observation using a standardised checklist in a population with high biomechanical exposures, and assess their validity in predicting the 1-year incidence of UWMSD. We used data from a French surveillance program for UWMSD implemented in a large shoe factory (Roquelaure et al. 2002;Roquelaure et al. 2001;Roquelaure et al. 2004). 


\section{METHODS}

\section{Design}

The UWMSD surveillance program implemented in the firm between 1996 and 2000 has been described in previous papers (Roquelaure et al. 2001;Roquelaure et al. 2002; Roquelaure et al. 2004). Only data from 1996 and 1997 were used for the present study. In 1996, workers were examined by the occupational physician in charge of health surveillance in this company. They completed a questionnaire about their working conditions at the same time that biomechanical exposures were assessed for each worker by direct observation and questioning by two specially trained assessors using a standardized checklist. Workers were examined again by the same occupational physician in 1997.

\section{Population}

Six of the twelve production units of the shoe factory, employing about 2,000 workers, were randomly selected and $20 \%$ of the blue-collar workers from each of these production units were randomly selected using the payroll rosters. In 1996, 253 blue-collar workers were included in the study and 191 of them were re-examined in 1997. In fact, about $10 \%$ of these workers had refused to answer a questionnaire about working conditions in 1996 and were not followed up in 1997. Moreover, because of the decrease in activity of one production unit (as a result of the economic crisis), only five of the six production units were finally included in the study in 1997 . As a result, only 191 of the 253 workers examined in 1996 were reexamined by the same physician during a 12 month period in 1997.

\section{Exposure assessments}

$\underline{\text { Self-administered questionnaire }}$ 
Physical exposure factors evaluated in the self-administered questionnaire in 1996 included repetitiveness, motion velocity, force, task precision, awkward postures, local mechanical stress and vibration exposure. All variables were self-assessed using a 6-point scale ranging from very low (=0) to very high $(=5)$ for each factor except vibration, which was assessed on a 5-point scale, ranging from never $(=0)$ to all the time $(=4)$.

The answers to these seven exposure questions were added into a "questionnaire score", with a possible range from 0 to 34. The "questionnaire score" was divided in two categories, using a threshold at 14 , chosen before the study to correspond to a mean score of two on each of the seven exposure variables in the questionnaire. The high physical exposure group included workers with a "questionnaire score" higher than or equal to 14 , and to the low physical exposure group, workers with a "questionnaire score" lower than 14.

\section{Observational method}

In 1996, biomechanical exposures were also assessed for each worker by a standardized jobsite work analysis. The work analysis was performed by direct observation and questioning by two specially trained assessors unaware of the medical status of individual workers. We used a modified version of the checklist proposed by Keyserling et al. (Keyserling et al. 1993). When the workers had two or more work situations, the analysis was performed on the most frequent. Job rotation between different work situations was recorded. Eighteen risk factors belonging to five classes of ergonomic factors were taken into account by the checklist: repetitiveness (work cycle $<30 \mathrm{sec}$; repetition of the same motions/exertions during more than $1 / 2$ of the work cycle), local mechanical contact stress (finger; palm; elbow; armpit), forceful manual exertion (weight over $4.5 \mathrm{Kg}, 2.7 \mathrm{Kg}, 1 \mathrm{Kg}$; slipping object or tool; pressing or pushing with the thumb, wearing gloves), awkward upper extremity posture (pinch grip; wrist deviation; twisting of the forearm; reaching down and behind the torso; use of elbow 
above mid-torso level), and hand tool usage (vibration exposure; cold; finger trigger motion, unbalanced or jerky tools or objects).

Exposure was recorded in a dichotomous fashion ("positive" versus "negative") for the risk factors "repetitiveness" and "local mechanical stress". Ergonomic factors regarding force, posture, equipment and tools had to be present during more than a third of the working cycle to be considered as "positive". An "observational score" was calculated for each worker as the sum of "positive" risk factors for either hand, ranging from 0 to 18.

The "observational score" was divided in two categories, using a threshold at 6 , chosen to dichotomize sample with a similar distribution in high or low physical exposure group of the "observational score". The high physical exposure group included workers with an "observational score" higher than or equal to 6, and to low physical group, workers with an "observational score" lower than 6.

\section{Health Outcomes}

All the workers were interviewed during the annual compulsory medical visit and examined using the same procedure using a structured examination (Roquelaure et al. 2001;Roquelaure et al. 2002;Roquelaure et al. 2004). In the present paper, the health outcome considered was having at least one of the nine UWMSD under review, i.e., tension neck syndrome, rotator cuff syndrome, lateral epicondylitis, medial epicondylitis, cubital tunnel syndrome, radial tunnel syndrome, carpal tunnel syndrome, Guyon's Tunnel syndrome and hand-wrist tendonitis.

Incident cases in the 1996-1997 period were defined as workers with at least one UWMSD in 1997 without any disorder in 1996.

\section{Statistical Analyses}


Agreement between the exposures assessed by self-administered questionnaire and observation was measured using Pearson's correlation to compare questionnaire and observation scores, and Cohen's Kappa to compare dichotomous exposures groups.

The associations between the two approaches (questionnaire and observation) and UWMSD incidence between 1996 and 1997 were studied using Student t test for the "questionnaire" and "observation" scores, and Fisher exact test (on exposure groups).

Receiver Operation Characteristics (ROC) curves were also drawn using 1996-1997 UWMSD incidence to confirm the choice of threshold and the measured the area under the curve (Goodenough et al. 1974). The ROC curve is a graphical method of assessing the characteristic of a diagnostic test. The ROC curve is constructed by plotting sensitivity against 1-specificity for all possible cut-off points on each scale.

Statistical Analysis Software was used for all analyses (SAS v8.2, SAS institute Inc, Mary, NC, USA). The level of significance chosen was $\mathrm{P}<0.05$.

\section{RESULTS}

Fifteen percent $(15 \% \mathrm{n}=39)$ of the workers did not complete the self-questionnaire and $8 \%$ $(n=21)$ did not undergo observation. The final sample included only workers who received both evaluations. No significant difference was observed between workers who underwent both evaluations and workers who did not, when considering gender, being over 45 years old, average number of years at the current job, smoking status or prevalence of UWMSD in 1996 $(\mathrm{p}>0.05)$.

The mean "questionnaire" score was at 20.9, the median was 22, the standard deviation was 7.0 and the range was $0-34$. The mean "observation" score was 8.2 , the median was 8 , the standard deviation was 2.3 and the range was $0-16$. 
The Pearson's correlation coefficient between the "questionnaire" and "observation" score was low, with a correlation coefficient of $0.06(\mathrm{p}=0.34$, figure 1$)$.

Most of the workers were categorized into the high exposure group, both in the questionnaire approach $(n=164,83.7 \%)$ and the observation approach $(n=176,89.8 \%)$. The Kappa was 0.21 [0.03-0.38], with $18 \%$ of subjects classified as high exposure by one method and low exposure by the other $(n=36)$.

Considering the 1996-1997 UWMSD incidence, there was no significant difference in the observational exposure scores between workers with and without incident UWMSD (table 1). The self-administered questionnaire performed better in distinguishing workers with UWMSD incidence, with a sensitivity of $96.8 \%$ and a negative predictive value of $95.5 \%$. However, the specificity and the positive predictive value were very low (26.2\% and $33.7 \%$ respectively). The ROC curves shown in figure 2 confirmed the choice of threshold, and illustrated the low areas under curve, 0.55 for the "questionnaire" score and 0.45 for the "observation" score.

\section{DISCUSSION}

This study suggests that self-reported exposure assessment with questionnaire, and exposure assessed with an observational method using the Keyserling et al. checklist, did not seem to evaluate the same dimensions. In a surveillance context of high physical exposure activities, the self-administered questionnaire, even with its modest predictive value, was a better predictor of future UWMSD than the observational method used here. In this group of workers characterized by high exposures, the exposures perceived by the workers were more predictive of future UWMSD than the observed exposures. For a surveillance context, the questionnaire may be an appropriate means of identifying workers at high risk of UWMSD. 
Several limitations to our study should be noted, including the size of the sample, the selection of the sample and the choice of evaluation methods. The population was unique because it included only workers with high exposure to physical risk factors, with more than $90 \%$ of workers categorized in the high exposure group, and with a high prevalence and oneyear incidence of UWMSD. The short range of physical exposure levels could explain the lack of predictability of physical exposures for future UWMSD. In a population with a larger variety of exposures, correlation and agreement between the self-report and observational approach would probably be better, with a higher predictive validity, especially for the observational method. When actual exposures in a study population fall within a small range, differences in perception of exposure may be more predictive of UWMSD than differences in actual exposures. This was true in our study of a homogenous highly exposed population, and is likely true of homogenous low-exposed populations as well.

The criteria chosen to examine physical exposure must be discussed, including items of the questionnaire and the choice of the checklist inspired by Keyserling. There is no consensus on the optimal exposure questionnaire for UWMSD risk, especially for surveillance purposes (Stock et al. 2005). However, the questions used in our study were similar to those used in previous studies, such as the Saltsa consensus criteria (Stock et al. 2005; Sluiter et al. 2001). These questions were also very close to the checklist items for the observational method. This checklist, derived from Keyserling et al., was developed to evaluate ergonomic risk factors associated with UWMSD (Keyserling et al. 1993). It was developed to study each risk factor separately in manufacturing (engine and pressed metal) and warehouse activities. It is possible that the checklist was not appropriate for all activities, for instance for force assessment, expressed in weight of tools or objects. Moreover, checklists are standardized but simplistic methods, compared to other observational methods: only the most frequent situations were explored with dichotomous exposure items, and without any weighting of these (some 
situations are probably worse than others). Several other checklists have been developed to assess UWMSD risk ( $\mathrm{Li}$ and Buckle 1999), beyond the ones focused on posture (Karhu et al. 1977;McAtamney and Nigel 1993): we could mention for instance the Concise Exposure Index (OCRA) developed in 1998 to quantify worker exposure to tasks involving repetitive movement of the upper limb (Occhipinti 1998), the Quick Exposure Checklist (QEC) developed also in 1998, which represents a UWMSD assessment checklist tool (Li and Buckle 1998), the Washington State SHARP Approach to exposure assessment (frequently called SHARP), developed in 2003 to evaluate awkward postures, high hand force, highly repetitive motions, repeated impact, heavy, frequent or awkward lifting of any part of the body (Marras and Karwowski 2006), or others based on the OSHA checklist (Silverstein 1997), or standards (IS0 11226). However, when the study was designed, most of the existing checklists had not yet been validated for surveillance purposes (Kilbom 1994;Li and Buckle 1999). At that time, the checklist derived from Keyserling et al. seemed the most appropriate standardized checklist for this plant, considering the kind of exposure and the only reasonable observational methods in the context of a first-level surveillance programs (Hagberg et al. 1995). In our study, self-reported exposure assessed by questionnaire is probably a less specific but more universal tool, but other recently validated checklists should also be studied.

Despite the limitations coming from the exposure assessment, our results were similar to others published results concerning agreement between self-administered and observational methods. In a recent systematic review, Stock et al. found few studies on the validity of workers' self-reports of physical exposure, compared with other ergonomic methods, especially concerning distal exposure (repetitive movements, hand/wrist postures, and hand use) (Stock et al. 2005). Some questions have performed well, such as those on postures in general, manual handling of more than or less than $10 \mathrm{~kg}$, and general level of physical effort. 
However, for repetitive movements, the agreement between self-reported and observed or directly measured methods was found to be fair-to-poor in four studies, with Kappas between 0.16 to 0.45 (Viikari-Juntura et al. 1996;Pope et al. 1998;Hansson et al. 2001;Leijon et al. 2002); for hand/wrist posture and for hand or finger use, only one study was been found, with poor agreement between methods (correlation coefficients between 0.08 and 0.31, and Kappas between -0.06 and 0.11) (Nordstrom et al. 1998).

Some studies have compared agreement between evaluation methods in subjects with UWMSD and subjects without (Viikari-Juntura et al. 1996;Nordstrom et al. 1998;Leijon et al. 2002). Our study was one of the first to compare the association between different physical exposure evaluations and UWMSD in a high exposure environment. Results found a low performance of the two evaluation, perhaps due to homogenously high exposures (Roquelaure et al. 2004;Descatha et al. 2005). However, the self-administered questionnaire seemed to be more accurate in identifying high risk workers in this setting of jobs with high physical demands. The poor agreement between self-administered and observational methods suggests that these methods may be complementary, and should be used in combination (Hagberg et al. 1995;Li and Buckle 1999;Spielholz et al. 2001;Leclerc 2005;Wiktorin et al. 1993;Wiktorin et al. 1999).

In conclusion, self-reported physical exposures assessed by questionnaire and observational assessment using a checklist derived from Keyserling et al. did not evaluate the same dimensions in this plant with high physical exposures. In this surveillance program, questionnaires were sensitive enough in the identification of workers with a high risk of developing disorders in the upper limbs. 


\section{ACKNOWLEDGMENTS}

We are grateful to Maria Melchior for her help in improving the English of the manuscript.

\section{REFERENCES}

Bernard BP. Musculoskeletal disorders and workplace factors: a critical review of epidemiologic evidence for work-related musculoskeletal disorders of the neck, the upperlimb, and low back. National Institute of Occupational Safety and Health. 97-141. 1997. Cincinnati.

Descatha A, Roquelaure Y, Mariel J, Evanoff B, Melchior M, Leclerc A. 2005. Predictive factors for incident musculoskeletal disorders in an in-plant surveillance programme. Occup Environ Med 62:e33.

Goodenough DJ, Rossmann K, Lusted LB. 1974. Radiographic applications of receiver operating characteristic (ROC) curves. Radiology 110:89-95.

Hagberg M, Silverstein BA, Wells R, Smith M.J., Herbert R, Hendrick H.W., Carayon P., Pérusse M. 1995. Work related musculoskeletal disorders (WMSDs). A reference book for prevention. Bristol: Taylor and Francis.

Hansson GA, Balogh I, Bystrom JU, Ohlsson K, Nordander C, Asterland P, Sjolander S, Rylander L, Winkel J, Skerfving S. 2001. Questionnaire versus direct technical measurements in assessing postures and movements of the head, upper back, arms and hands. Scand J Work Environ Health 27:30-40.

Karhu O, Kansi P, Kuorinka I. 1977. Correcting working postures in industry: A practical method for analysis. Appl Ergon 8:199-201.

Keyserling WM, Stetson DS, Silverstein BA, Brouwer ML. 1993. A checklist for evaluating ergonomic risk factors associated with upper extremity cumulative trauma disorders. Ergonomics 36:807-831.

Kilbom A. 1994. Assessment of physical exposure in relation to work-related musculoskeletal disorders--what information can be obtained from systematic observations? Scand J Work Environ Health 20 Spec No:30-45.

Leclerc A. 2005. Exposure assessment in ergonomic epidemiology: is there something specific to the assessment of biomechanical exposures? Occup Environ Med 62:143-144.

Leijon O, Wiktorin C, Harenstam A, Karlqvist L. 2002. Validity of a self-administered questionnaire for assessing physical work load in a general population. J Occup Environ Med 44:724-735.

Li G, Buckle P. 1998. The development of a practical tool for musculoskeletal risk assessment. In: Robertson SA, editor. Contemporary Ergonomics. London: Taylor and Francis.p 442-7. 
Li G, Buckle P. 1999. Current techniques for assessing physical exposure to work-related musculoskeletal risks, with emphasis on posture-based methods. Ergonomics 42:674-695.

Marras WS, Karwowski W. 2006. Fundamentals and Assessment Tools for Occupational Ergonomics. The Occupational Ergonomics Handbook. 1024 p.

McAtamney L, Nigel CE. 1993. RULA: a survey method for the investigation of work-related upper limb disorders. Appl Ergon 24:91-99.

Nordstrom DL, Vierkant RA, Layde PM, Smith MJ. 1998. Comparison of self-reported and expert-observed physical activities at work in a general population. Am J Ind Med 34:29-35.

Occhipinti E. 1998. OCRA: a concise index for the assessment of exposure to repetitive movements of the upper limbs. Ergonomics 41:1290-1311.

Pope DP, Silman AJ, Cherry NM, Pritchard C, Macfarlane GJ. 1998. Validity of a selfcompleted questionnaire measuring the physical demands of work. Scand J Work Environ Health 24:376-385.

Ricci MG, De Marco F, Occhipinti E. 1998. Criteria for the health surveillance of workers exposed to repetitive movements. Ergonomics 41:1357-1363.

Roquelaure Y, Mariel J, Dano C, Fanello S, Penneau-Fontbonne D. 2001. Prevalence, incidence and risk factors of carpal tunnel syndrome in a large footwear factory. Int J Occup Med Environ Health 14:357-367.

Roquelaure Y, Mariel J, Dano C, Leclerc A, Moisan S, Penneau-Fontbonne D. 2004. Surveillance Program of Neck and Upper Limb Musculoskeletal Disorders: Assessment Over a 4 Year Period in a Large Company. Ann Occup Hyg 48:635-642.

Roquelaure Y, Mariel J, Fanello S, Boissiere JC, Chiron H, Dano C, Bureau D, PenneauFontbonne D. 2002. Active epidemiological surveillance of musculoskeletal disorders in a shoe factory. Occup Environ Med 59:452-458.

Scientific committee for musculoskeletal disorders of the ICOH. 1996. Musculoskeletal disorders: Work-related risk factors and prevention. Int J Occup Environ Health239-246.

Silverstein, B. The use of checklists for upper limb risk assessment.From experience to innovation IEA1997.

Sluiter BJ, Rest KM, Frings-Dresen MH. 2001. Criteria document for evaluating the workrelatedness of upper-extremity musculoskeletal disorders. Scand J Work Environ Health 27 Suppl 1:1-102.

Spielholz P, Silverstein B, Morgan M, Checkoway H, Kaufman J. 2001. Comparison of selfreport, video observation and direct measurement methods for upper extremity musculoskeletal disorder physical risk factors. Ergonomics 44:588-613.

Stock SR, Fernandes R, Delisle A, Vezina N. 2005. Reproducibility and validity of workers' self-reports of physical work demands. Scand J Work Environ Health 31:409-437. 
Viikari-Juntura E, Rauas S, Martikainen R, Kuosma E, Riihimaki H, Takala EP, Saarenmaa K. 1996. Validity of self-reported physical work load in epidemiologic studies on musculoskeletal disorders. Scand J Work Environ Health 22:251-259.

Wiktorin C, Karlqvist L, Winkel J. 1993. Validity of self-reported exposures to work postures and manual materials handling. Stockholm MUSIC I Study Group. Scand J Work Environ Health 19:208-214.

Wiktorin C, Vingard E, Mortimer M, Pernold G, Wigaeus-Hjelm E, Kilbom A, Alfredsson L. 1999. Interview versus questionnaire for assessing physical loads in the population-based MUSIC-Norrtalje Study. Am J Ind Med 35:441-455. 
Figure 1: "Observation" score correlated with the "questionnaire" score, $n=196$. 
Figure 2: ROC (Receiver Operation Characteristics) curves on "questionnaire" (area under ROC curve $=0.55$ ) and "observation" scores (area under ROC curve $=0.45$ ), based on upperlimb work related musculoskeletal disorders incidence between 1996 and 1997.

The points on the curve correspond to all possible cut-off points on each score.

$c o=$ Cut-off 
Table 1: Comparison of "questionnaire" and "observation" scores between workers who developed upper-limb work related musculoskeletal disorders between 1996 and 1997, and workers who did not.

1996-1997 non 1996-1997 incident

incident cases $n=89 \quad$ cases $n=32 \quad p=*$

$\begin{array}{llll}\text { n } & \% & \text { n } & \%\end{array}$

\begin{tabular}{|c|c|c|c|c|c|c|}
\hline "Observation" & High exposure & & & & & \\
\hline \multirow[t]{5}{*}{ score } & group $($ score $\geq 6)$ & 77 & 86.5 & 30 & 93.8 & 0.35 \\
\hline & Low exposure & & & & & \\
\hline & group $($ score $<6)$ & 12 & 13.5 & 2 & 6.2 & \\
\hline & $\operatorname{Mean}($ s.d.) & 7.9 & $(0.5)$ & 7.6 & (1.8) & 0.41 \\
\hline & Median & 8 & & 7 & & \\
\hline "Questionnaire" & High exposure & & & & & \\
\hline \multirow[t]{5}{*}{ score } & group $($ score $\geq 14)$ & 59 & 73.8 & 30 & 96.8 & 0.007 \\
\hline & Low exposure & & & & & \\
\hline & group $($ score $<14)$ & 21 & 26.2 & 1 & 3.2 & \\
\hline & Mean (s.d.) & 19.7 & (7.6) & 21.3 & $(5.1)$ & 0.21 \\
\hline & Median & 20.5 & & 21 & & \\
\hline
\end{tabular}

* p-values of Fisher exact and Student t tests where appropriate. 